\title{
Assessment of survivability of surface combatants after damage in the sea environment
}

\author{
Evangelos. Boulougouris ${ }^{1}$ (M), Stuart. Winnie ${ }^{1}$ (SM), Apostolos. Papanikolaou ${ }^{2}$ (FL) \\ 1. Naval Architecture, Ocean and Marine Engineering, University of Strathclyde, Glasgow G4 0LZ, Scotland \\ 2. School of Naval Architecture and Marine Engineering, National Technical University of Athens, Athens, 15773, Greece \\ E-mail: evangelos.boulougouris@strath.ac.uk
}

\begin{abstract}
The operating conditions of modern warships, in the natural sea environment, have a significant influence on their survivability in the event that watertight integrity is lost. Up to now, the consideration of sea and weather conditions has been implicitly accounted for in a naval ship's damaged stability assessment. This paper outlines a probabilistic approach to assessing a naval ship's damage stability, in which some of the limitations of the currently used damage stability criteria are identified, including the validity of the assumption of moderate sea states at the time of damage. An investigation into the operability of a frigate design found that there is a significant increase in the risk of a ship's loss when changing the operational area from the North Atlantic to the North Pacific. A remarkable additional finding of the study showed that the assumed distribution for the damage penetration has no significant effect on the ship's survivability due to the way modern combatants are designed.
\end{abstract}

KEY WORDS: survivability, probabilistic damage stability, naval surface ships

\section{NOMENCLATURE}

A Attained subdivision index

b Non-dimensional damage penetration

B Maximum Beam

$\mathrm{H}_{\mathrm{s}} \quad$ Significant wave height

$\mathrm{L}_{\mathrm{sk}} \quad$ Sure kill length

$\mathrm{L}_{\mathrm{ss}} \quad$ Sure save length

$\mathrm{p}_{\mathrm{i}} \quad$ Probability of compartment(s) i flooding after damage

$\mathrm{S}_{\mathrm{f}} \quad$ Survivability of ship particular function, $\mathrm{F}$

$\mathrm{S}_{\mathrm{i}} \quad$ Local survival index

$\mathrm{x} \quad$ Non-dimensional longitudinal damage position

y Non-dimensional damage length

$\theta_{\text {roll }} \quad$ Rollback angle

\section{INTRODUCTION}

Surface combatants such as corvettes, frigates, destroyers and cruisers differ greatly from other ship categories in that they are designed and built to support high-end combat operations while operating in hostile environments. A passenger or merchant vessel must be able to withstand accidental damage from collision or grounding whereas a surface combatant must be able to withstand the effects of purposely-incurred damages caused by sophisticated modern anti-ship weapons. Due to this survivability and the ability to 'fight hurt' is a vital design objective for surface combatants.
One of the main contributors to the survivability of a surface ship is her vulnerability to weapon effects and as such, the damage stability and floatation characteristics have a direct influence on the vulnerability of the vessel. The role of the designer is therefore to minimize the ships vulnerability through optimal watertight subdivision by considering a large amount of damage cases and operational scenarios. Such scenarios should take into consideration the harsh environmental conditions in which modern surface ships are expected to operate. In addition to subdivision, vulnerability can be reduced through methods such as hardening of the hull however; both methods face constraints such as space requirements for vital systems and weight limitations.

Most major navies assess the damage stability of their vessels using a variation of the empirically defined criteria proposed by Sarchin and Goldberg (1962). The semi-empirical deterministic criteria are based largely on WWII battle damage experience and have been criticised as being outdated (Surko, 1994). The criteria used by major navies such as the U.S. Navy (USN) and Royal Navy (RN) have been reviewed over the years; however, no significant changes have been made. Although the criteria have served their purpose to date, there are serious concerns about their limitations and applicability to modern naval ships. Some of the shortfalls of the criteria include (Surko, 1994);

- The capability of modern warships to survive damage from current threats, in demanding environmental conditions, is not known

- Modern hull forms and construction techniques differ greatly from the ships used to determine the criteria

- Assumption of moderate wind and sea conditions at the time of damage 
Table 1.

Current UK and US Damaged Stability Criteria for Surface Combatants

\begin{tabular}{|c|c|c|c|c|}
\hline \multicolumn{2}{|c|}{ Criteria } & UK Defstan 02-900 & U.S.N DDS 079-1 & GERMANY BV 1030-1 \\
\hline \multirow{3}{*}{ Damage Length } & $\mathrm{LWL}<30 \mathrm{~m}$ & 1 Compartment & 1 Compartment & 1 Compartment \\
\hline & $\mathrm{LWL}>30 \mathrm{~m}$ & 2 Comp or at least $6 \mathrm{~m}$ & 2 Comp or at least $6 \mathrm{~m}$ & $18 \%$ LWL $-3.6 \mathrm{~m}$ (Not exceeding $18 \mathrm{~m}$ ) \\
\hline & $\mathrm{LWL}>92 \mathrm{~m}$ & $\operatorname{Max}\{15 \% \mathrm{LWL}$ or $21 \mathrm{~m}\}$ & $15 \% \mathrm{LWL}$ & - \\
\hline \multirow{4}{*}{ Permeability } & Watertight void & $97 \%$ & $95 \%$ & $98 \%$ \\
\hline & Accommodation & $95 \%$ & $95 \%$ & $95 \%$ \\
\hline & Machinery & $85 \%$ & $85-95 \%$ & $85 \%$ \\
\hline & Stores etc. & $80-95 \%$ & $60-95 \%$ & $80 \%$ \\
\hline \multirow{5}{*}{$\begin{array}{l}\text { Stability \& } \\
\text { Reserve } \\
\text { Buoyancy }\end{array}$} & $\theta_{\text {roll }}$ & $15^{\circ}$ & $10^{\circ}$ (for 5000t ship) & - \\
\hline & Angle of list or loll & $<20^{\circ}$ & List $<15^{\circ}$ & $<25^{\circ}$ with $40 \mathrm{kts}$ wind \\
\hline & Area A1 & $>1.4 \mathrm{~A} 2$ & $>1.4 \mathrm{~A} 2$ & $>1.4 \mathrm{~A} 2$ \\
\hline & Longitudinal GM & $>0$ & - & - \\
\hline & Buoyancy & $\begin{array}{l}\text { Longitudinal trim less than } \\
\text { required to cause down- } \\
\text { flooding }\end{array}$ & 3in margin line & to bulkhead deck \\
\hline
\end{tabular}

This suggests that neither the designer nor operator have a clear understanding of the survivability performance or operational limitations of a vessel. It is well known that the operation and safety of a ship largely depends on its behaviour in waves, consequently the vulnerability of the vessel is therefore affected by the sea state at the time of damage. The Falklands conflict highlighted the harsh environments in which modern surface combatants are required to operate and survive.

Current deterministic criteria (shown in Table 1) imply a moderate sea state at the time of damage $\left(\mathrm{H}_{\mathrm{S}}=8 \mathrm{ft}\right)$, which is independent of ship's size and operating profile. However, in order to adequately represent the harsh environments which could be faced, a survival sea state must be directly specified for the ship under investigation at the time of damage. This will allow a rational assessment of vessel operability in terms of survivability for a specific sea environment. In addition to the limitation of moderate sea states, the current deterministic criteria fall short through the application of a defined damage length, which results in only a predetermined number of damage scenarios being assessed. In practice, due to the large diversity of modern threats, the damage extent is random and can vary extensively in location and magnitude, thus all probable damages should be assessed to give the designer a full understanding of the vessels survivability performance. Currently the German Navy is the only major navy know to include a probabilistic assessment of survival in their criteria (BV 1030-1). However, this is only conducted when the vessel fails to achieve the outlined the deterministic criteria and is used to aid in decision-making.

In contrast to the current naval standards, which have slowly progressed over the years, the International Maritime Organization (IMO) has made significant advances in upgrading the safety standards of passenger and merchant vessels. The acceptance of the new harmonized probabilistic damage stability framework of SOLAS 2009, for the damage stability assessment of passenger and dry cargo vessels, shows that the maritime industry and regulatory bodies are convinced this is the right way forward.

Boulougouris and Papanikolaou (2004) previously presented a methodology for the probabilistic damaged stability assessment of naval combatants and its application to design optimisation. The methodology, which is presented herein, addresses several of the shortfalls of the current deterministic criteria and its application. The presented probabilistic methodology requires that a survival sea state is explicitly defined, which enables the survivability performance in different operational areas to be evaluated. Furthermore, the methodology allows the quantification of the risk that the vessel will be lost due to damage. Thus, minimal risk can become a design objective and the surface ship can be optimised to minimise risk while still being efficient and economical.

This paper extends the design concept presented earlier by Boulougouris and Papanikolaou $(2004,2013)$ for the assessment of survivability of surface combatants after damage. In this respect, a study was undertook in order to determine which damage penetration probability distribution is most suitable for the application to naval ships. A further study aimed to quantify any differences in risk between operating in the North Atlantic, where many warships were traditionally designed to operate, and the North Pacific. The probabilistic methodology was applied to the damage stability assessment of a generic frigate operating in specified areas at the time of damage.

\section{SURVIVABILITY}

Surface combatants are designed to operate in hostile environments in which sophisticated sensors and weapon systems have been designed to detect, target and engage them. In such 
environments, it is vital that the ship maintains its ability to remain mission capable even in the event of being damaged.

The capability of a surface combatant to continue to carry out its designated mission in a threat environment is referred to as survivability. There are two main aspects, which both influence the overall probability of survival:

- $\quad$ Susceptibility - Inability of the ship to avoid being damaged in operation and is also referred to as the probability of being hit $\left(\mathrm{P}_{\mathrm{H}}\right)$

- Vulnerability - Inability of the ship to withstand the effects of a threat weapon and is also referred to as the probability of serious damage or loss when hit $\left(\mathrm{P}_{\mathrm{K} / \mathrm{H}}\right)$

The product of susceptibility and vulnerability can therefore mathematically describe the probability of a kill. Hence, the mathematical relationship between survivability $\left(\mathrm{P}_{\mathrm{S}}\right)$, susceptibility $\left(\mathrm{P}_{\mathrm{H}}\right)$ and vulnerability is as follows (Ball \& Calvano, 1994);

$P_{S}=1-\left(P_{H} \times P_{K / H}\right)$

Susceptibility is made up of all the factors which expose the ship to a threat weapons effects, such as its signatures. In order for an aggressor to successfully score a hit on a surface combatant they must first detect, classify and target the vessel followed by a successful launch and engagement of a weapon (Ball and Calvano, 1994). This sequence of events is referred to as the 'kill chain.' The ability of a surface combatant to disrupt and break the threats kill chain is therefore directly related to its susceptibility. The fundamental means of susceptibility reduction is through reducing the detectability of the ship. This can be achieved through minimizing its signatures such as its Radar cross section (RCS). However even the stealthiest vessel can have its position revealed through electronic emissions e.g. external communication attempts or through making radar scans. A number of different hard and soft kill methods can also be utilized to break the kill chain e.g. jamming, decoys, close in weapons system (CIWS) etc.

Vulnerability is the post hit aspect of a naval ships survivability and is the degree to which a hit or multiple hits can cause serious damage. The primary effect of a threat weapon such as an Air to Surface Missile (ASM) is the initial explosion, the resulting highpressure wave will damage and destroy nearby structures and equipment. The secondary effects include fire and progressive flooding which can be more detrimental to the ship than the initial blast. Following a hit there are several different levels of a ship kill which can occur, in this case the definition given by Ball \& Calvano (1994) is referred to;

- $\quad$ System Kill - damage of one or more compartments which leads to the failure of a ship system.

- Mission Area Kill - damage which leads to the loss of a mission critical area such as AAW

- Mobility Kill - damage which leads to the ship being immobilised through the loss of propulsion or steering.

- Total Ship Kill - damage which leads to the loss of the ship through insufficient buoyancy, loss of transverse stability or abandonment due to fire.

The focus of this paper is on the assessment of vulnerability to flooding and from herein a ship kill will refer to a total ship kill. As descried by Ball \& Calvano there is a hierarchy of different ship kills; a system kill can easily lead to a mission area, mobility or total kill. Thus, optimal subdivision and hardening of vital spaces is used to limit the extent of damage and also prevent secondary effects such as fire and flooding from spreading. A naval ships vulnerability is dependent on its size, subdivision, armouring, location of equipment and the degree of redundancy available. "Cheap kills" should be avoided through protection of magazines and weapon stores from weapon effects.

It has always been favourable to shoot the 'archer' before he has the chance to fire his 'arrows' in combat, due to this some navies have focused their attention on susceptibility reduction. This allows them to engage a threat before they can be engaged or avoid detection all together. Some naval design philosophies have included the 'design for peace' concept, as the probability of sustaining damage during operations in peacetime is very low. They will therefore accept that in the event of a hit the vessel will be out of action for some time or have limited participation in the operation. However the sophistication and diversity of modern threats implies that even with the advances in stealth and selfdefence technology naval combatants can expect to be hit by antiship missiles (and mines and torpedoes) in substantial numbers (Harney, 2010). When combined with the fact that naval fleet sizes are shrinking it is clear that the ability to absorb multiple hits and 'fight hurt' is more important than ever.

Therefore, there is a need to assess vulnerability from the early design stages so that any vulnerabilities in the design can be identified and rectified before parts of the design start to become fixed. The current damage stability criteria used by most of the major navies treat the vulnerability of the ship as a property with a deterministic outcome, namely pass or fail. This approach does not allow the quantification of the level or survivability, which is a rational probabilistic quantity, which makes it difficult to compare alternate designs and impossible to optimise for enhanced survivability.

\section{ENVIRONMENT}

It is evident that the operating conditions of modern warships, such as sea state, have a significant influence on their survivability, but this is difficult to assess when dealing with traditional deterministic approaches. This is due to the sea conditions at the time of damage being implicitly accounted for within the current deterministic damage stability criteria.

The criteria currently used by the USN and RN assume moderate sea states at the time of damage which includes sea states up to 
and including sea state 4 (8ft wave height). However, these moderate conditions are readily exceeded in areas such as the North Atlantic and North Pacific (Surko, 1994). A database of reported sea states from RN and Royal Fleet Auxiliary (RFA) vessels showed that RN ships spent approximately $24 \%$ of their time at sea states greater than 4 between 1968 and 2000 (Heywood \& Smith, 2009).

Hence, this underlying assumption of sea state fails to represent the harsh environments in which a surface combatant is expected to survive. Unlike merchant vessels, a surface combatant cannot chose whether to sail or change course to avoid harsh environment. Due to requirements for a surface combatant to remain in a mission area, it is crucial from a survivability standpoint to account for the expected environmental conditions in these areas. Therefore, sea states for the appropriate operational areas at the time of damage should be directly accounted for within the damage stability assessment.

Due to the wide variety of areas which a surface combatant can be expected to operate, it is essential that the most likely operational areas and those critical from a survival point of view are identified. A survivability envelope approach can be used which defines a range of sea state conditions in which the ship is required to survive. This envelope would consist of extreme sea state data for the identified areas. This could include areas from the calmer South China Sea to the harsh environments of the North Pacific.

In this paper a mathematical model is presented for calculating ship survivability which allows for a specific survival sea state in the case of damage to be input (Boulougouris \& Papanikolaou, 2004,2013). The application of this methodology opens the possibility to assess ship survivability on the basis of mission performance requirements such as the sea conditions faced in mission areas. The method was applied to a generic frigate, which meets the relevant existing deterministic criteria. Several different areas of operation were considered in order to observe the influence of operational area, or sea state, on the survivability.

\section{VULNERABILITY ASSESSMENT}

Boulougouris and Papanikolaou (2004, 2013) previously presented a methodology for the probabilistic damaged stability assessment and its application to design optimisation. It is based on the fundamentals of the probabilistic damage stability concept for passenger vessels introduced by Wendel (1960) and its derivatives (IMO Resolution A.265; IMO MSC.19 (58); IMO MSC.216 (82)) which are used to assess the ships level of safety after damage. The probabilistic approach uses the probability of survival after damage as a measure of the ships safety in the damaged condition. The approach considers the following probabilities of events as being relevant to the ships damage stability;

- The probability that a compartment or group of compartments i may be flooded (damaged), $\mathrm{p}_{\mathrm{i}}$.

- The probability that the ship will survive after flooding of the compartment or group of compartments $\mathrm{i}$ under consideration, $\mathrm{S}_{\mathrm{i}}$.

The $\mathrm{p}$ factor is purely dependant on the geometry of the watertight arrangement of the ship whereas the s factor is dependent on the calculated stability after damage. The total probability of survival is expressed by the attained subdivision index, $\mathrm{A}$, and is the given by the sum of the product of $\mathrm{p}_{\mathrm{i}}$ and $\mathrm{s}_{\mathrm{i}}$ for each compartment and compartment group, i along the ships length.

$A=\sum_{i} p_{i} \cdot s_{i}$

In order for a vessel to comply with the IMO probabilistic method for passenger and cargo ships (IMO MSC.216 (82)) the attained subdivision index must be greater than or equal to the required index. This ensures that the vessel is designed with an acceptable level of risk. The required attained index is based on the number of passengers carried, safety equipment on-board and the length of subdivision. The required index $(\mathrm{R})$ of the ship is consistent with the mean value of the attained index (A) from a sample of existing ships, which supposedly offer an acceptable level of risk. This consists of ships of a similar size and number of passengers, which have acceptable damage stability/ survival characteristics. Similarly, for warships an acceptable level of risk should be specified by either the owner (navy) or approval authority (NATO/ classification society).

For naval vessels there is a probability that the ship will be targeted, engaged and take a hit leading to the flooding of one or more compartments. The damage may occur at any point along the ship's hull and can vary extensively is magnitude. The extent of damage is dependent on both the characteristics of the target (ship) and the threat weapon. As the survivability of the vessel is determined by the vulnerability and susceptibility, the probability distribution for damage of a naval ship relates these characteristics.

The probability of survival of a particular function of the ship, $\mathrm{S}_{\mathrm{f}}$, can be extracted from the total attained index, which represents ship's floatability and stability after damage. If $\mathrm{j}^{*}=\left\{\mathrm{j}_{1}, \mathrm{j}_{2}, \mathrm{j}_{3}, . ., \mathrm{j}_{\mathrm{n}}\right\}$ is the set of compartments that host all systems of the particular function $\mathrm{F}$, then the damage to any compartment which is included in $\mathrm{j}^{*}$ will impair the ship from function $\mathrm{F}$. Therefore, the probability of survival of the particular function, $\mathrm{S}_{\mathrm{f}}$, is calculated using the following formula:

$$
S_{f}=\sum_{i} p_{i} \cdot S_{i}-\sum_{j} p_{j} \cdot S_{j}
$$

include the compartment set $j *$. For example, $S_{f}$ can represent the ships mobility function where $\mathrm{j}^{*}$ will represent the group of compartments which house the ships propulsion system.

\section{Determining $\mathbf{p}_{\mathbf{i}}$}


The probability of a damage case occurring is based on the longitudinal, transverse and vertical damage probability damage density distributions. Initially the longitudinal damage extent will be discussed.

During the initial stages of a naval ship's design, when there is a lack of refined information for the threat's signature distribution along the ship it can be assumed that the probability of weapon impact along the hull follows a basic mathematical distribution, such as the piecewise linear distribution. Boulougouris and Papanikolaou (2004) propose that for air-to-surface missile (ASM) threats, a piecewise linear distribution with maximum probability amidships can be used. As both the ships radar profile and heat emissions due to machinery and exhaust are highest at amidships, this is the most likely aim point of the weapon. For contact mines, a linear distribution can be assumed (Harmsen \& Krikke, 2000). Thus the impact point probability density function in the missile's case with a piecewise linear distribution is;

$$
\operatorname{imp}(x)=\left\{\begin{array}{cc}
4 x & x \leq 0.5 \\
-4 x+4 & x \geq 0.5
\end{array}\right.
$$

The damage length probability density distribution is based on the concept of the Damage Function used in the theory of Defence Analysis (Przemieniecki, 1994). The well-known lognormal distribution is considered the most appropriate for this case. Therefore, the damage length probability density distribution is given by the following formula;

$$
\operatorname{Dam}(y)=\frac{1}{\sqrt{2 \cdot \pi} \cdot \beta \cdot y} \cdot \exp \left[-\frac{\ln ^{2}(y-\alpha)}{2 \beta^{2}}\right]
$$

Where;

$$
\alpha=\sqrt{L_{S S} L_{S K}}, \beta=\frac{1}{2 \sqrt{2} z_{s s}} \ln \left(\frac{L_{S S}}{L_{S K}}\right)
$$

Where; $\mathrm{L}_{\mathrm{SK}}$ is the sure kill length, which means that $\mathrm{d}\left(\mathrm{L}_{\mathrm{SK}}\right)$ $=0.98, \mathrm{~L}_{\mathrm{SS}}$ is the sure save length, which means $\mathrm{d}\left(\mathrm{L}_{\mathrm{SS}}\right)=0.02$ and $z_{S S}$ is a constant equal to 1.45222 . For defining the damage extent range, it is a common approach in naval ship design to consider 2 or 3 damaged compartments around the detonation compartment, especially in the absence of blast resistant bulkheads (Erkel \& Galle, 2003). Estimates that are more detailed may result from a careful risk assessment based on live firing tests analysis or the analysis of data from actual engagements. Other methods include empirical formulas linking the damage range with the type and weight of the warhead or from the use of damage lengths/extents defined in current deterministic damage stability regulations. In the latter case, which is the one proposed by Boulougouris and Papanikolaou (2004), a first approximation of the $\mathrm{L}_{\text {SS }}$ can be taken according to naval codes DefStan 02-900 and DDS-079 as 0.15L (see Table 2). The authors state that the $\mathrm{L}_{\mathrm{SK}}$ can be assumed equal to $0.02 \mathrm{~L}$.
By combining the impact point and damage length density functions the probability of damage lying between the boundaries $\mathrm{x}_{1}$ and $\mathrm{x}_{2}$ or a naval ship's compartments is;

$$
p_{i}=\int_{0}^{y} \operatorname{Dam}(y) \int_{x_{1}+\frac{y}{2}}^{x_{2}-\frac{y}{2}} \operatorname{imp} p(x) d x d y
$$

The equations resulting from substituting $\operatorname{Dam}(\mathrm{y})$ and $\operatorname{Imp}(\mathrm{x})$ into equation 6 were presented in Boulougouris and Papanikolaou (2004).

\section{Transverse Distribution}

In the case of the transverse extent of damage, it is well known that the damage penetration from air delivered weapons can extend across the full beam in the case of smaller vessels. The damage penetration is dependent on both the threat weapon characteristics and the characteristics of the vessel. In the case of the threat weapons the main factors include the size of the warhead, type of fuse (e.g. contact or time delay) and if it is a fragmentation weapon or just high explosive. The internal structure of the target vessel has a great influence on whether the explosion will be contained, or extend across multiple compartments. In addition, the volume of the compartment in which the warhead detonates has an influence on the blast pressure waves, which result in the most damage.

Due to the complex nature of the problem, it is reasonable to assume that the transverse extent of damage follows a basic mathematical distribution in the initial stages of design. In this case, it was necessary to make several assumptions, in the event of an impact it is unlikely that the damage will extend only slightly beyond the side shell. It has also been assumed that in most cases it is unlikely that damage will extend across the full beam. Thus, the log-normal distribution has been used to represent the damage penetration distribution as this is probably the most accurate representation of the damage function (Przemieniecki, 1994). The probability that a damage penetration is less than a given penetration depth, $b$, is therefore;

$$
r=\frac{1}{2}\left\{\operatorname{erf}\left[\frac{\ln (b / \alpha)}{\sqrt{2} \beta}\right]+1\right\}
$$

Where;

$$
\alpha=\sqrt{R_{S S} R_{S K}}, \beta=\frac{1}{2 \sqrt{2} z_{s S}} \ln \left(\frac{R_{S S}}{R_{S K}}\right)
$$


Where $\mathrm{R}_{\mathrm{SK}}$ is the sure kill radius which means that $\mathrm{d}\left(\mathrm{R}_{\mathrm{SK}}\right)=0.98$, $\mathrm{R}_{\mathrm{SS}}$ is the sure save radius which means $\mathrm{d}\left(\mathrm{L}_{\mathrm{SS}}\right)=0.02$ and $\mathrm{z}_{\mathrm{SS}}$ is a constant equal to 1.45222 .

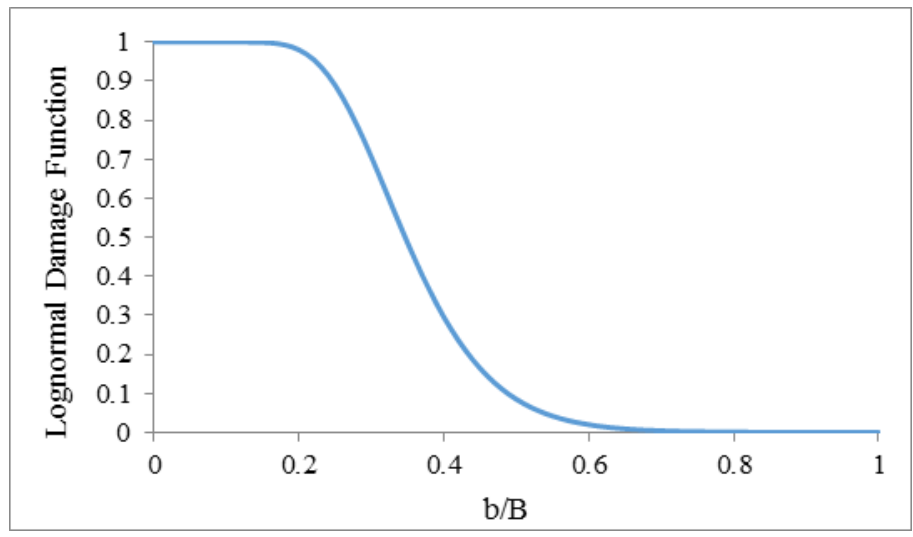

Fig. 1 Penetration lognormal damage function

The methodology to account for the longitudinal subdivision in the calculation of $p_{i}$ uses the same basic equations outlined in part B regulation 7-1 of the SOLAS 2009 (IMO, 2006) probabilistic damage stability regulations.

\section{Vertical Distribution}

The vertical extent of damage may also vary depending on the weapon's characteristics. In a surface combatant such as a frigate or a destroyer there are three watertight boundaries vertically, namely the tanktop, the damage control deck and the main deck (Fig. 2). Excessive vertical watertight boundaries are avoided by design as high flooding can lead to poor stability thus it can be favourable to allow lower decks to flood. In the case of an air delivered weapon (e.g. Anti-Ship Cruise Missile) it will generally detonate close to the waterline causing greater damage above the waterline and the tank top will most likely remain intact. However, in the case of an underwater weapon (e.g. contact mine or torpedo) which detonates close to the keel, the damage control deck will likely remain intact from the blast. The problem with an underwater explosion is that modern under-keel torpedoes are capable of causing extensive damage to the hull girder of even a cruiser sized ship, often this is sufficient to cause breaking and sinking of the ship. Such cases are not covered in the proposed methodology, as the maintenance of structural integrity is a perquisite for the assessment of the ships damage stability.

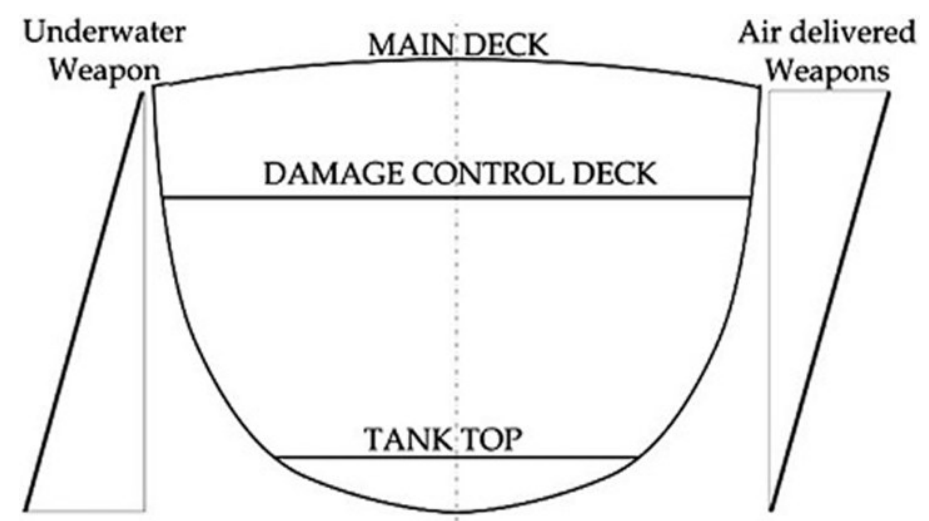

Fig. 2 Naval Ship Vertical Watertight Boundaries

For a hit by an air-delivered weapon, a linear distribution for the probability density function of the vertical extent of damage can be used. Its maximum is at the main deck and the minimum at the keel, the opposite is valid for an underwater weapon. By considering the vertical extent of damage, the effect of the position of vertical watertight boundaries on the overall survivability of the vessel can be observed. In order to take into account both threats a weighting factor can be applied according to an operational analysis of the potential threats.

\section{SURVIVAL INDEX $\mathrm{S}_{\mathrm{i}}$}

As previously mentioned the German Navy are the only navy known at the time of writing to outline a probabilistic assessment of survival after damage in their current criteria. In the case of BV 1030-1 (BWB, 2001), the probability of survival after damage (W- value) is to be calculated if the outlined deterministic criteria are not met. Thus, if the criteria cannot be met through design measures or modifications, the vessel can still be approved if the risk is deemed acceptable. The probability of survival after damage (W) is calculated using sectional area probabilities. It does not represent the overall probability of survival as only a pre-determined set of damage cases are assessed as opposed to considering all probable damage scenarios. Although this method does not give an accurate representation of a ships probability of survival after damage, the German navy have recently developed a new set of probabilistic criteria.

In this case, the presented approach used to assess the probability of survival after damage is a probabilistic quasi-static approach adjusted for the currently valid, semi-empirical deterministic criteria for naval ships (Boulougouris \& Papanikolaou, 2013).

Table 2. Probabilistic damage stability criteria for naval combatants

\begin{tabular}{|c|l|c|}
\hline \multirow{2}{*}{$\mathrm{s}_{\mathrm{i}}=1$} & $\mathrm{Q}_{\text {roll }}=25 \mathrm{deg}$ & Wind Speed = According to Defstan 02-900 \\
\cline { 2 - 3 } & $\mathrm{A}_{1} \geq 1.4 \mathrm{~A}_{2}$ & Min Freeboard $\geq 3$ in $+0.5\left(\mathrm{H}_{\mathrm{s}}(0.99)-8 \mathrm{ft}\right)$ \\
\hline \multirow{2}{*}{$\mathrm{s}_{\mathrm{i}}=\mathrm{P}\left(\mathrm{H}_{\mathrm{s}} \leq 8 \mathrm{ft}\right)$} & \multicolumn{2}{|c|}{ Ship meets Defstan 02-900 damage Stability Criteria } \\
\hline \multirow{2}{*}{$\mathrm{s}_{\mathrm{i}}=0$} & $\mathrm{Q}_{\text {roll }}=15 \mathrm{deg}$ & Wind Speed = According to Defstan 02-900 \\
\cline { 2 - 3 } & $\mathrm{A}_{1} \leq 1.05 \mathrm{~A}_{2}$ & Longitudinal trim $<$ required to cause downflooding \\
\hline
\end{tabular}


The approach considers the probability of survival after damage and is based on quasi-static survival criteria such as those used by the Royal Navy and US Navy. These criteria were developed from real life damage incidences of WWII and although the current criteria have been under criticism as being outdated, they have proved reliable over the years and thus there have been no significant changes. One of the main criticisms of the current criteria is the fundamental assumption that the sea conditions at the time of damage are "moderate." This constraint was lifted in the herein presented methodology, with the requirement for a specific survival sea state at the time of damage.

This allows the correction of these requirements by consideration of the probability of exceedance of an $8 \mathrm{ft}$ wave height, which is considered as basis for the current deterministic criteria. The wave height is used in the criteria in order to define $\varphi_{\text {roll }}$, the roll amplitude due to wave action. It was also the underlying assumption behind the guidelines for establishing the watertight features/closures to prevent progressive flooding. Thus, any attempt to change the wave amplitude must take into account changes in both $\varphi_{\text {roll }}$ as well as the margin line or equivalent.

From Table 2, it can be seen that the criteria allow the sea state at the time of damage to be directly accounted for within the assessment. One of the parameters is $H_{s}(0.99)$ which represents the significant wave height with a $99 \%$ probability of nonexceedance for the specified area. This wave height is used for the definition of maximum freeboard, which considers the probability of sinking without capsize in the criteria. In addition to $H_{\mathrm{s}}(0.99)$, the probability that an $8 \mathrm{ft}$ will not be exceeded, $\mathrm{P}$ $\left(\mathrm{H}_{\mathrm{S}} \leq 8 \mathrm{ft}\right)$, is also specified. This parameter defines the probability of survival when the ship meets the current $\mathrm{RN}$ criteria.

The wind speed is another important parameter which needs to be considered, however given the small probability of exceeding the values given by RN and U.S Navy standards, the values were left unchanged (approximately 33 knots for a $3500 t$ frigate).

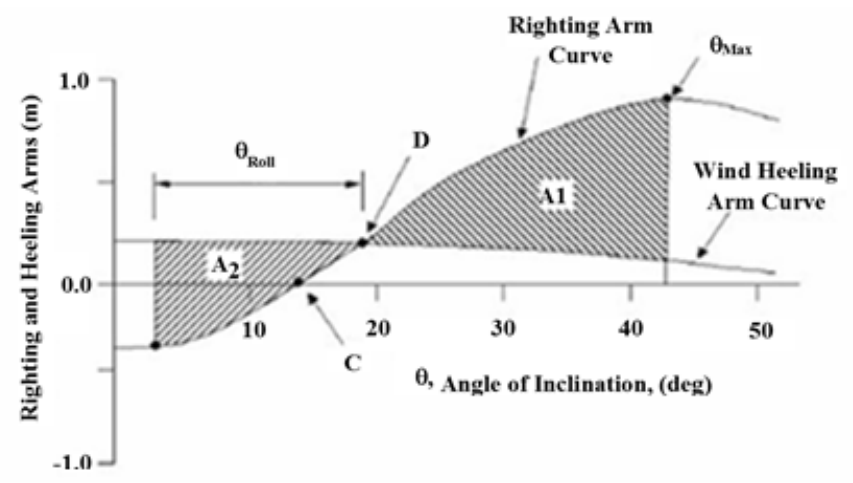

Fig. 3 Damaged Ship GZ Curve

Table 2 shows the criteria which were applied in the frame of a probabilistic approach to assess the survivability of a generic frigate. For intermediate stages, interpolant values can be used. Fig. 3 shows the meaning of various notions of the righting arm curve. $\theta_{\text {roll }}$ is the rollback angle, from point $\mathrm{D}$, which represents the roll amplitude due to wave action. Point $\mathrm{C}$ represents the initial heel angle after damage and point $\mathrm{D}$ represents the wind heeling arm equilibrium.

In order to implement the criteria the following values can be used. For ships operating in North Atlantic, $\mathrm{P}\left(\mathrm{H}_{\mathrm{S}} \leq 8 \mathrm{ft}\right)$ would be 0.56 and 0.90 for the East Mediterranean Sea (Athanassoulis \& Skarsoulis, 1992). For the North Pacific, $\mathrm{P}\left(\mathrm{H}_{\mathrm{S}} \leq 8 \mathrm{ft}\right)$ would be 0.42 (Lee, 1995) and 0.71 for the South China Sea (Haveman et al, 2006). Therefore, a combatant, meeting the U.S. Navy criteria for warships, should have according to the proposed criteria a $56 \%$ probability of survival in the North Atlantic for a damage length not exceeding the current regulations (Ochi, 1978). This probability will increase to $90 \%$ probability of survival in the Mediterranean Sea and to $71 \%$ in the South China Sea. However, in the case of the North Pacific, the probability of survival will decrease to $42 \%$. Obviously, a similar methodology can be introduced for auxiliary naval vessels. The minimum required values for compliance could be estimated after application of the above procedure to sample/existing ships.

\section{CASE STUDY}

The herein outlined probabilistic damage stability framework for surface combatants was applied to a generic frigate model, which was defined in the Maxsurf® package (Bentley Systems, 2013). The stability of the vessel was assessed using Maxsurf's stability module. The ship's main particulars are given in Table 3 and the 3D hull model is shown in Fig 4.

Table 3. Main Particulars

The arrangement (Fig. 5) is typical for a frigate of this size with a centreline passageway providing an un-flooded route across the

\begin{tabular}{|cc|}
\hline \multicolumn{1}{|c|}{ Main Particulars } \\
\hline Loa $(\mathrm{m})$ & 148.1 \\
Lwl (m) & 137 \\
Twl (m) & 4.31 \\
Depth (m) & 9.3 \\
Displacement (tons) & 4528 \\
\hline
\end{tabular}

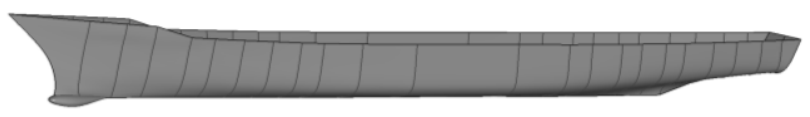

Fig 4 Frigate 3D Hull Model 
Table 4. $\mathrm{p}$ factor for 1 compartment damages

\begin{tabular}{|cccccccc|}
\hline Room & $\mathrm{NZ}$ & $\mathrm{x}_{1}$ & $\mathrm{x}_{2}$ & $\mathrm{x}_{1} \mathrm{u}$ & $\mathrm{x} 2 \mathrm{u}$ & $\mathrm{y}$ & $\mathrm{Pi}$ \\
\hline 1 & 1 & 0 & 13 & 0.000 & 0.095 & 0.095 & 0.007 \\
2 & 1 & 13.0 & 23.5 & 0.095 & 0.172 & 0.076 & 0.011 \\
3 & 1 & 23.5 & 29.3 & 0.172 & 0.214 & 0.042 & 0.002 \\
4 & 1 & 29.3 & 41.1 & 0.214 & 0.301 & 0.087 & 0.030 \\
5 & 1 & 41.1 & 51.6 & 0.301 & 0.377 & 0.076 & 0.029 \\
6 & 1 & 51.6 & 62.0 & 0.377 & 0.453 & 0.076 & 0.036 \\
7 & 1 & 62.0 & 72.5 & 0.453 & 0.529 & 0.076 & 0.042 \\
8 & 1 & 72.5 & 79.5 & 0.529 & 0.581 & 0.052 & 0.011 \\
9 & 1 & 79.5 & 89.1 & 0.581 & 0.650 & 0.070 & 0.026 \\
10 & 1 & 89.1 & 102.3 & 0.650 & 0.747 & 0.097 & 0.046
\end{tabular}

Fig. 6 Contribution of Various Damage Cases to the Attained Index Three decks form the horizontal watertight boundaries, namely the main deck ( $1^{\text {st }}$ deck $)$, damage control deck $\left(2^{\text {nd }}\right.$ deck $)$ and the tank top $\left(4^{\text {th }}\right.$ deck $)$

$\begin{array}{llllllll}14 & 1 & 128 & 137 & 0.935 & 1.000 & 0.065 & 0.001\end{array}$

Initially the deterministic assessment was carried out in which all damage cases had to meet the criteria outlined in DefStan 02-900. The damage length specified $(15 \% \mathrm{Lwl})$ resulted in a damaged length of $20.55 \mathrm{~m}$, thus the minimum length of $21 \mathrm{~m}$ was used to define the damage cases. This resulted in mainly 3 compartment cases. Several different transverse extents were taken for each damage case including $\mathrm{B} / 5, \mathrm{~B} / 2$ and penetration across the full beam to ensure to worst possible cases were considered. As the frigate model was designed to this standard, all damage cases fulfilled the criteria.

In terms of the longitudinal extent of damage, initially up to 6 adjacent zones were considered. However the contribution to the attained index of these cases were found to be negligible, thus damage cases up to 4 adjacent zones were defined in Maxsurf stability. The formulae for the calculation of the probability of damage occurring, $\mathrm{p}_{\mathrm{i}}$, from equation 6 were applied to the basis vessel and the results for single compartment damage cases are given in Table 5. For the subdivision arrangement under consideration, 1 compartment damage cases were found to contribute approximately $27 \%$ to the attained index whereas 2,3 and 4 compartment cases contribute $60 \%, 11 \%$ and $1 \%$ respectively as shown in Fig. 6.

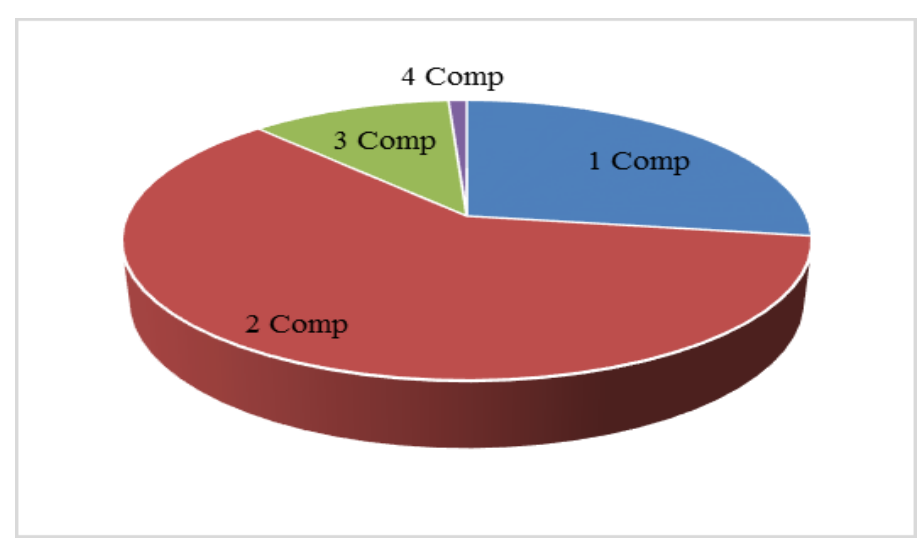

\section{Transverse Distribution}

In order to develop a robust probabilistic framework for naval ships, systematic calculations must be carried out on a representative sample of ships, which comply with the current damage stability regulations. In this respect, a study was conducted in order to explore the effects of the damage penetration distribution on the overall survivability. The aim of this study was to provide insight into which distribution is most suitable for naval ships.

Initially the lognormal damage function was altered in order to represent different transverse damage extents. The aim was to gain insight into how the damage penetration distribution influences the overall survivability. In the lognormal penetration distribution, the maximum damage penetration is expressed by $\mathrm{R}_{\mathrm{SS}}$ (Equation 7) which represents the $98^{\text {th }}$ percentile damage penetration depth. For the study, damage penetrations up to the full beam of the vessel were considered.

Several different maximum damage penetrations were considered ranging from $0.1 \mathrm{~B}$ to $\mathrm{B}$. This range across the full beam was considered in order to gain insight into the severity of asymmetrical flooding. The lognormal damage functions for several of the damage penetration depths can be seen in Fig. 7.

A number of damage scenarios were ran for each of the distributions, with different maximum damage penetration (Rss). These are shown in table 4 along with their respective Rsk values. It was found that the sure kill radius (Rsk) had little influence on the overall results. Therefore, the minimum value of Rsk was used for each of the maximum damage penetrations. This was the minimum value which resulted in the integral of the lognormal damage function summing to one. For all the scenarios the operational area was taken as the North Pacific. 


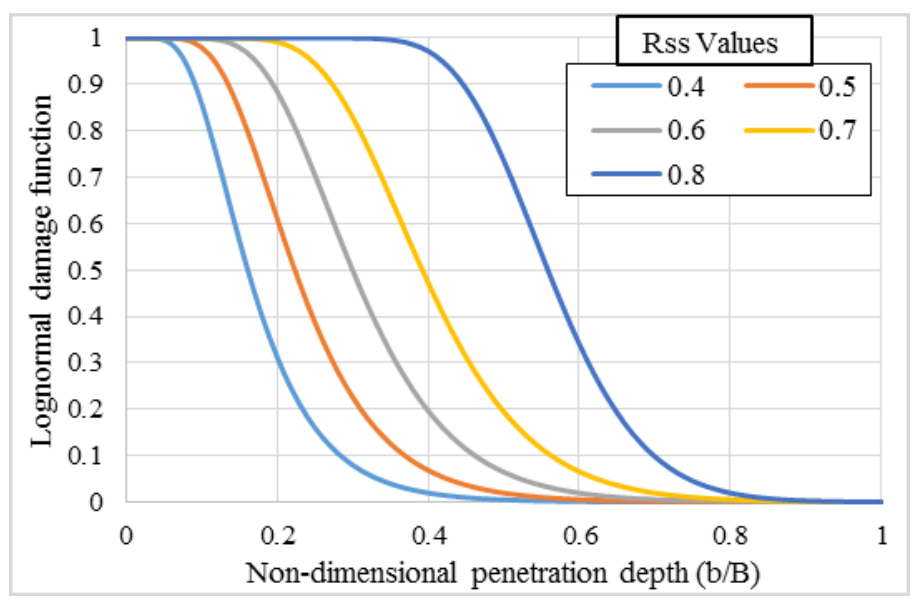

Fig. 7 Lognormal Damage Function for Various Rss Values

Table 4. Rss and Rsk Values

\begin{tabular}{|ccc|}
\hline Rss & Rsk & Rsk/Rss \\
\hline 0.1 & 0.01 & 0.100 \\
0.2 & 0.025 & 0.125 \\
0.3 & 0.04 & 0.133 \\
0.4 & 0.065 & 0.163 \\
0.5 & 0.1 & 0.200 \\
0.6 & 0.15 & 0.250 \\
0.7 & 0.22 & 0.314 \\
0.8 & 0.39 & 0.488 \\
0.9 & 0.64 & 0.711 \\
0.95 & 0.81 & 0.853 \\
0.99 & 0.96 & 0.970 \\
\hline
\end{tabular}

Initially the damage scenarios were ran for the deepships condition. Fig. 8 shows the attained index against maximum damage penetration (Rss) for these scenarios. It can be readily observed from the figure that there is only a small difference in attained index between the minimum (0.946) and maximum (0.959). The difference between these two points was found to be approximately $1.3 \%$, thus in this condition asymmetrical flooding does not appear to significantly influence the survivability. From this loading condition, it appears that the lognormal function with a maximum damage penetration of either $0.5 \mathrm{~B}$ or $0.6 \mathrm{~B}$ is most suitable. For the scenarios where the maximum damage penetration is greater than $0.7 \mathrm{~B}$, the probability of occurrence of the lesser penetrations becomes negligible. Thus, the influence of asymmetrical flooding is not fully accounted for. Taking any maximum damage penetration greater than these values could therefore result in an over conservative estimate of a naval ships survivability.

Fig. 8 also suggests that for the light seagoing condition there is a significant difference in attained index between the different maximum damage penetrations used. In this condition, a $9 \%$ difference in attained index was observed between the $0.5 \mathrm{~B}$ and full beam maximum penetration damage extent. This illustrates that in the lighter loading conditions the effect of asymmetrical flooding can be more detrimental to the survivability of the vessel. Once again, the results suggest that a maximum damage penetration should not be taken greater than $0.6 \mathrm{~B}$ as this can lead to overestimating the survivability of the vessel.

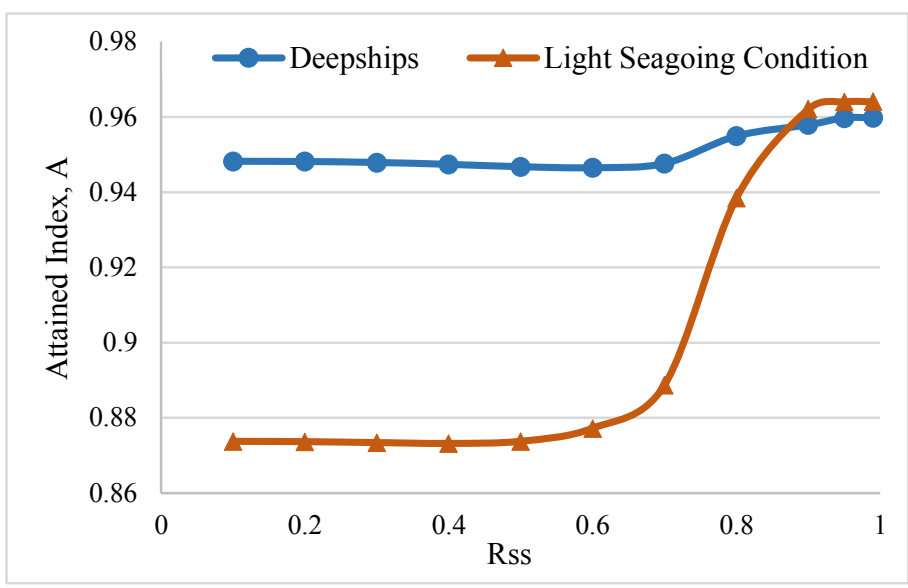

Fig. 8 Attained Index against Rss (Sure Save Radius)

Due to the way in which modern warships are designed the damage penetration distribution does not have much influence on the deepships condition. Longitudinal subdivision is generally avoided, where possible, in naval ship design due to the large list angles which may develop following asymmetric flooding. Note that currently, the transverse penetration, which would result in the worst stability condition is used as criterion for naval ships and this differs from passenger ship requirements were collision damage is limited to $\mathrm{B} / 2$. Due to these requirements, any longitudinal subdivision that could potentially lead to unsymmetrical flooding is avoided. For the frigate under consideration the asymmetrical flooding is the result of the tank arrangement. Hence, this is unavoidable highlighting the large differences in survivability for the light seagoing condition.

Thus, when applying the probabilistic framework the most suitable distribution should be utilised. From the results the lognormal damage function with a sure save radius of $0.5 \mathrm{~B}$ seems most practical. The results also illustrate that in order to further enhance the survivability of a surface combatant greater attention should be paid to limiting the longitudinal extent of damage either through optimal subdivision or with the use of blast resistance bulkheads. The results also suggest that asymmetrical flooding due to tanks has a negative effect on the survivability in light seagoing conditions however; it will be very difficult to negate this through design.

Through the application of the probabilistic framework the designer can produce figures which can be used to easily identify weak points in design. For example the plot of $1-\mathrm{p}_{\mathrm{i}}(1-\mathrm{K})$ against ' $x$ ' as shown in Fig. 9 highlights cases where there will be significant damaged heel. Such figures can aid the designer in optimizing longitudinal barriers such as tanks. 


$$
K=\sqrt{\frac{\theta_{\max }-\theta_{e}}{\theta_{\max }-\theta_{\min }}}
$$

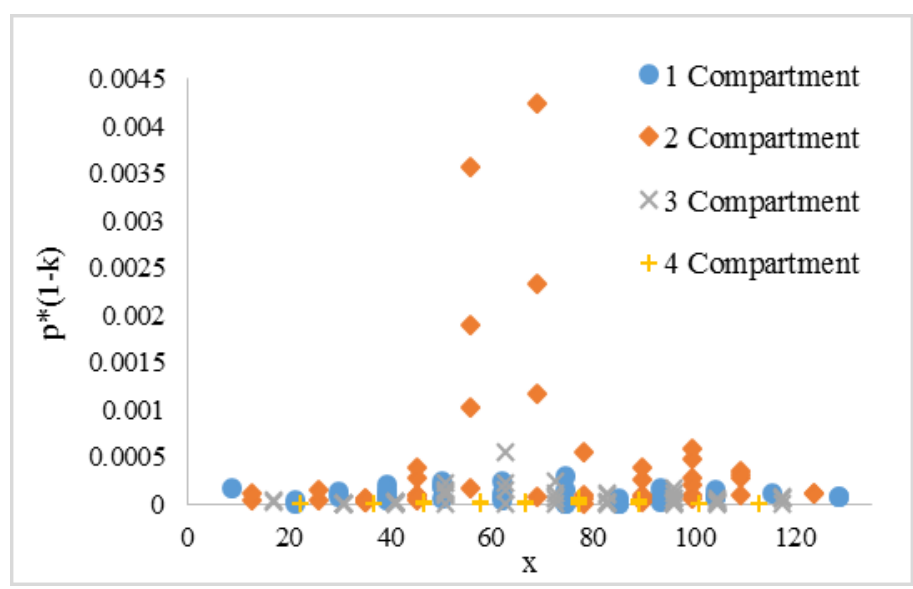

Fig.9 1-p (1-k) against $x$

Where, $\theta_{\mathrm{e}}$ is the equilibrium heel angle for the damage case and $\theta_{\max }$ and $\theta_{\min }$ represent the maximum and minimum allowable list angles following damage, which can be taken from the deterministic criteria.

\section{Operational Area}

In order to investigate the influence of operational area and sea state at the time of damage on survivability, three different operational areas across the globe were assessed in this study, namely the North Atlantic, North Pacific and South China Sea. The North Atlantic scenario was considered as this was the area of operation focused on by the RN, where warships such as the Type 23 were designed to conduct anti-submarine warfare; of course, the North Atlantic is also a prime operational area for USN ships. The North Pacific and South China Sea were also considered: these areas were assessed due to increased tensions and territorial disputes in these waters. Although only these areas were considered in this study, the application of the present probabilistic concept and suggested criteria allows the inclusion of any operational area.

The relevant sea state data for the operational areas under consideration is as follows. For the North Atlantic Scenario, we assume $\mathrm{P}(\mathrm{Hs} \leq 8 \mathrm{ft})=0.56$ and $\mathrm{Hs}(0.99)=10 \mathrm{~m}$, for the North Pacific P $(\mathrm{Hs} \leq 8 \mathrm{ft})=0.42$ and Hs $(0.99)=11.2 \mathrm{~m}$. For the South China Sea Scenario we assume P $(\mathrm{Hs} \leq 8 \mathrm{ft})=0.71$ and $\mathrm{Hs}(0.99)$ $=5.4 \mathrm{~m}$.

The data for each of the operational areas were processed by the criteria shown in table 2. For the frigate under consideration at full load condition the attained index was found to be $A=0.98$ for the North Atlantic, $\mathrm{A}=0.95$ for the North Pacific Scenario and $\mathrm{A}=0.989$ for the South China Sea.

A 3\% increase in risk was observed when changing the operational area from the North Atlantic to the North Pacific.
Although the survivability of the vessel under consideration is high for both operational areas this may not always be the case. The attained index may be satisfactory for one operational area; however, for other operational areas the ship may fail to meet the required attained index prompting the designer to take action. Thus, in order for the designer and operator to fully understand the performance of the vessel the most probable and high risk operational areas should be identified and assessed from the early design stages.

The probabilistic methodology presented by Boulougouris and Papanikolaou (2004) allows for the application of a survivability envelope which defines a range of sea state conditions in which the ship is expected to survive.

\section{CONCLUSION}

Boulougouris and Papanikolaou (2004, 2013) previously presented a methodology for the probabilistic damaged stability assessment of naval combatants and its application to design optimisation. This paper supplements their work by investigating the effect of the damage penetration distribution on the survivability. In addition, the influence of operational area has been studied further to observe the influence of changing the area of operation from the North Atlantic to the North Pacific.

The study found that the damage penetration distribution is not an 'issue' for surface combatants, as commonly any longitudinal subdivision that will result in asymmetrical flooding is avoided by design. It was found that the lognormal damage function can accurately represent the damage from an air delivered weapon and sufficiently account for asymmetrical flooding.

The application of the presented methodology allows the use of more realistic operating conditions such as sea state at the time of damage giving the designer a better understanding of the damaged ship's performance and limitations. The results observed when changing the operational area from the North Atlantic to the North Pacific showed a decrease in the probability of survival due to more severe environmental conditions. Thus by considering operational areas in the survivability assessment from the early design stages, the risk can be minimised to acceptable levels for all areas which are critical from a survivability perspective.

Furthermore, the use of the presented methodology allows a holistic approach to be taken to surface ship stability. This allows the ship's subdivision to be optimised for minimum risk, making survivability a distinct feature of the design. Combined with the more realistic operating conditions such as sea state, the approach will give the designer and operator a better understanding of the damaged ships performance and limitations.

\section{REFERENCES}

Athanassoulis, G., \& Skarsoulis, M. (1992). Wind and wave atlas of the North-Eastern Mediterranean Sea. NTUASMHL. 
Ball, R. E., \& Calvano, C. N. (1994). Establishing th fundamentals of a surface ship Survivability Design Discipline. Naval Engineers Journal 106, 71-74.

Bentley Systems. (2013). Maxsurf Marine Vessel Analysis and Design Software. Retrieved from http://www.bentley.com/enUS/Products/Maxsurf/Marine+Vessel+Analysis+and+ Design.htm

Boulougouris, E. K., \& Papanikolaou, A. D. (2004). Optimisation of the Survivability of Naval Ships by Genetic Algorithms. 3rd Int. EuroConference of Computer Applications and Information technologies in the Maritime Industries.

Boulougouris, E., \& Papanikolaou, A. (2013). Risk-based design of naval combatants. Ocean Engineering 65, 4961.

Chang, D. B., \& Young, C. S. (2010). Probabilisitic Estimates of Vulnerability to Explosive Overpressures and Impulses. Journal of Physical Security, 10-29.

Department of US Navy. (2002). DDS 079-1 Stability and Buoyancy of U.S Naval Surface Ships. Department of US Navy.

Erkel, A. v., \& Galle, L. F. (2003). TNO-PML Developments of Blast Resistant Doors and Walls. 8th International Marine Design Conference, (pp. 753-764). Athens.

Federal Office of Defence Technology and Procurement (BWB), 2001. BV 1030-1.

Ferreiro, L. D., \& Stonehouse, M. H. (1991). A Comparative Study of US and UK Frigate Design. SNAME Transactions Vol. 99, 147-175.

Harney, R.C., 2010. Broadening the Trade Space in Designing for Warship Survivability. Nav. Eng. J. 122, 49-63.

Haveman, C., Parliament, J., Sokol, J., Swenson, J., \& Wagner, T. (2006). Design of a Floating, Production, Storage, and Offloading Vessel for Operation in the South China Sea. Texas: Texas A\&M University.

Heywood, M., \& Smith, D. (2009). Application of Dynamic VLines to Naval Vessels. 10th International Conference on Stability of Ships and Ocean Vehicles, (pp. 1-9).

IMO. (2006). Resolution MSC.216(82) Adoption of Amendments to the International Convention for the Safety of Life at Sea.

IMO. (2007). MSC.1/Circ.1226 Interim Explanatory Notes to the Solas Chapter II-1 Subdivision and Damage Stability Regulations. IMO.

Kotiranta, R. (2006). The assessment of a naval vessel's survivability against explosion in air based on a $3 D$ product model. Helsinki University of Technology.

Lee, W. T. (1995). Global Wave Statistics for Structural Design. Maryland: Naval Surface Warfare Center.

MOD. (2010). MAP 01-024 Stability of Surface Ships part 1.

NATO/PfP. (2004). NATO/PfP Working Paper on Small Ship Design (Unclassified). NATO.

Ochi, M. K. (1978). Wave statistics for the design of ships and ocean structures. SNAME Transactions 86, 47-76.

Payne, C. M. (2006). Principles of Naval Weapons Systems. Naval Institute Press.
Przemieniecki, J. S. (1994). Mathematical Methods in Defence Analysis. American Institure of Aeronautics and Astronautics.

Said, M. O. (1995). Theory and practice of total ship survivability for ship design. Naval Engineers Journal, 191-203.

Sarchin, T. H., \& Goldberg, L. L. (1962). Stability and buoyancy Criteria for U.S. Naval Surface Ships. 70.

Surko, S. W. (1994). An Assessment of Current Warship Damaged Stability Criteria. Naval Engineers Journal, 120-131.

UK MOD. (2013). DEFSTAN 02-900 Part 1.

Wendel, K. (1960). Die Wahrscheinlichkeit des Überstehens von Verletzungen. Journal of Ship Technology Research, 47-61. 